\title{
ERRATUM
}

\section{EUROPEAN JOURNAL OF DRUG METABOLISM AND PHARMACOKINETICS}

1995, Vol. 20, No. 1, pp. 73-77

\section{Effect of sulfated xylans during the interaction of $\left[{ }^{125}\right.$ I]-thrombin with antithrombin III or heparin cofactor II of human plasma}

\section{R.B. SIMMONS, G.R. NEWTON and V.M. DOCTOR}

Chemistry Department and Cooperative Agriculture Research Center, Prairie View A\&M University, Prairie View, Texas, USA

Fig I : Effect of OSXS and heparin on the complexation of [ $\left[{ }^{125} \mathrm{I}\right]$-thrombin with AT-III and HC-II of human plasma. Please refer to Materials and Methods for details. Lane A and B represented $40 \mu \mathrm{g}$ and $8 \mu \mathrm{g} / \mathrm{ml}$ of heparin, respectively, while lanes D and E represented $40 \mu \mathrm{g}$ and $8 \mu \mathrm{g} / \mathrm{ml}$ of OSXS, respectively. The plasma control (lane C) did not show complex formation with $\left[{ }^{125} \mathrm{I}\right]$-thrombin. The mixture was incubated for $30 \mathrm{~s}$ before heating with the reducing mixture.

The upper legends to Figure 1 in this manuscript were incorrectly positioned (p.75).

The legend 'Thr-HC-II' should have been above 'Thr-AT-III' instead of below. This agrees with the correct results as given in Table I of the published article : i.e. OSXS (Lanes D \& E) enhanced the interaction of $\left[{ }^{125} \mathrm{I}\right]$-thrombin with both AT-III and HC-II, whereas heparin (Lanes A \& B) only enhanced the interaction of $\left[{ }^{125} \mathrm{I}\right]$-thrombin with AT-III.

We apologise for any problems this may have caused. 